\title{
Analysis of the Spanish industry economical losses due to interruptions in the electricity supply
}

\author{
D. Coll-Mayor ${ }^{1}$, J. Pardo ${ }^{2}$ and M. Pérez-Donsión ${ }^{2}$ \\ ${ }^{1}$ Department of Physics \\ University of Balearic Islands (UIB) \\ Palma de Mallorca, 07122 Illes Balears (Spain) \\ Phone/Fax number:+0034 986 812685, e-mail: debora.coll@uib.es \\ ${ }^{2}$ Department of Electrical Engineering \\ E.T.S.I.I., Vigo University \\ Campus of Lagoas - Marcosende, 36310 Vigo (Spain) \\ Phone/Fax number:+0034 986 812685, e-mail: j.pardo@uvigo.es, donsion@uvigo.es
}

\begin{abstract}
This paper focuses on the evaluation of the economic consequences of a lack of power quality in the industrial sector. The term Power Quality includes, in general, a set of boundary conditions which allow electrical systems connected to the grid to function in their intended manner, without significant loss of performance or life. Therefore, the operation of the power system outside these boundaries directly impacts on the economic performance of the whole system. The evaluation of the economical loses derived of this fact has been matter of several studies, mostly applied to individual cases, with calculation methodologies either too complicated to be applicable, either needing a large input of data most dealing with confidentiality issues or either based on particular cases and impossible to extrapolate. The methodology proposed in this paper is relativelly easy to apply, covers a large range of cases and is based on data directly retrieved from estatistics of the Spanish government free downladable and free of confidentiality issues. An example of the application of this methodology and an analysis of the results is also provided.
\end{abstract}

\section{Key words}

Power Quality, Economical Evaluation, Voltage Sag, Harmonics, Power Economics.

\section{Introduction}

A set of methodologies for evaluating the economical implication of a lack of power quality were analyzed in reference [1]. From all the methodologies evaluated, it can be stated that they can be classified in four main groups:

- First, the methodologies that provide a simple and easy to apply methodology but needing a great amount of data in order to provide an approximation to the real value of the losses. With the added problem that gather some of these data has to do with dealing with confidentiality issues.
- Second, the methodologies that are not a general methodology but a complete analysis of a target industry, based therefore on a particular case. The more sofisticated ones even need the sensitivity curves for every load present in the target industry.

- Third, the methodologies that try to give a general approach to be applied to different kind of industries but only giving the main parameters considered for a few particular cases. And not enough information of how to calculate such parameters for other industries.

- Fourth, the last group are methodologies that are based on subjective parameters which are difficult to evaluate and quantify.

It can be concluded that non of the analyzed methodologies provides a simple, easy and general way to evaluate economical losses due to power quality problems in a target industry.

This paper proposes a new methodology based on data directly retrieved from estatistics of the Spanish government free downladable and free of confidentiality issues.

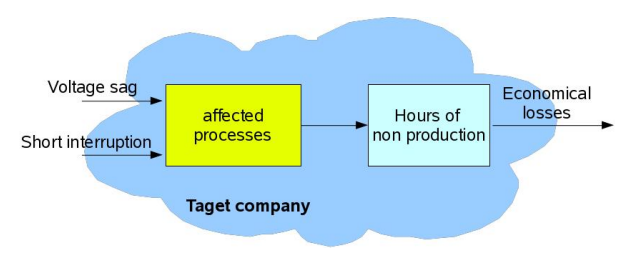

Fig. 1: Evaluating losses because of power quality issues in a target industry

This methodology separates the problem in two parts, see figure 1. The first one is the evaluation of the consequences of the lack of power quality in terms of Equivalent Hours of non Production (EHnP) and 
secondly, the calculation of the economical value of this EhnP.

This work will focus on the second part: the calculation of the economical value of the EhnP due to interruptions of the power supply or voltage dips.

\section{Valuation of the economical losses}

The valuation of economical losses is based on the evaluation of EHnP as benefit not produced.

The benefit produced by the different activities which composed the economical system in Spain is evaluated and accounted by the Spanish National Countability (CNE) system. The CNE provides a list of parameters which conforms basic statistics. The data used for constructing these statistics is provided by different sources which are confronted by a single countable frame.

The statistics are given annually, but three times a year the estimations are examined and evaluated until they became definitive. All this proceeding targets to obtain a reliable source of data to estimate the national accounts, in an effective and reliable way. The statistics are gathered together in three groups of activity branches disaggregation.

Based on the statistical information provided by the 27 activity branches disaggregation, the benefit per hour of the different activity branches is provided. This benefit per hour can also represent the lack of benefit (or losses) if one hour the activity stops. Therefore, the lack of energy supply would produce the activity to stop and therefore the losses are provoked.

\section{A. Mathematical model}

The methodology proposed is based on the mathematical model, defined as follows:

Value $=E H n P \cdot V o L L \cdot E L P$

Where:

Value represents the value of the economical losses [k€]

EHnP Equivalent Hours of non Production [h]

VoLL Value of Lost Load [€/kWh]

ELP Equivalent Lost Power [GW]

The evaluation of the different parameters will be explained in the following sections and an example of application of the mathematical model will be developed.

\section{B. Limitations of the methodology}

The statistical information available does not include partial loses, in case of lossing only a part of the production machinery. The production in the industry is also evaluated as constant per hour, not considering different impacts of an interruption or sag at different hours.

\section{C. $E H n P$}

$\mathrm{EHnP}$ data is an input, that has to be known. The estimation of this parameter is a difficult matter, since it depends on factors like level of automatization of the industry, internal protocols in case of failure, type of machinery, time of day, time of week, etc. The only assumption that can be made is that the EHnP is proportional to the lenght of interruptions and to the depth of the sag.

Throughout this work, the EHnP will be considered as time of power interruption. The power interruptions can be divided in short power interruptions and long power interruptions.

In the Spanish case as for most European countries, for long power interruptions --more than three minutes interruptions-- time and energy lost are recorded and this statistical data can be freely downloaded.

In the Spanish case for short interruptions -less than three minutes- or voltage sags of different magnitude, no statistical information is available. If the study has to be done for short interruptions, it should be necessary before to start to have available a record of at least one year measurements (of short interruptions and voltage sags) in the feeder to the industry target. After that, voltage sags would be classified depending of its depth and a weighting factors depending on sag magnitude should be used. Data about weighting factors can be found in references [2] and [3].

\section{VoLL}

VoLL is considered as the added value generated by an activity divided by the energy consumed by this activity.

A valuation of this VoLL can be found in [4], [5]. These references provide values centered in a determined environment such as the UK or Netherlands. In order to make this methodology worldwide applicable, in this work importance has been given to find a source of data for the calculation of the VoLL which can be easily extrapolated to different environments.

The valuation of this VoLL can be done: (1) at region level: using general data from a concrete region; (2) at activity level: using a general data for a particular activity in a region and; (3) at company level: using data from a particular company.

At region level there are different possibilities, it can be considered a general value for countries or for regions insite the contry. At country level if the VoLL shall be used for comparing the energy behaviour of the industry in different countries and can be estimated as: 


$$
V o L L_{\text {country }}=\frac{G D P}{T E C}
$$

Where:

GDP represents the Gross Domestic Product [€], which is the basic measure for evaluating the economical output of a country.

TEC represents the Total Energy Consumption [GWh], which is the electrical energy a country consums in one year.

Both data for European countries can be found in statistics from the European Eurostat agency. For countries outsite Europe, both data can also be found in the statistical database from the United Nations.

\section{E. ELP}

The ELP (Equivalent Lost Power) is the lost of power experienced in an interruption. The lost of power depends on many variables such as the hour in the day or the day in the week when the interruption took place. In the worst case, the power lost will correspond to the peak power consumption in the company. In the application of this methodology and in order to maximize the consequences, the power lost will always be considered as the peak power consumption of the industry.

\section{Example of application}

An example of application of the methodology is provided for the evaluation of losses in five representative regions in Spain: Andalucía, Cataluña, Galicia, Madrid and País Vasco during the year 2006.

\section{A. Evaluation of the EHnP}

The EHnP in this case will be assumed to be the Customer Average Interruption Duration Index (CAIDI).

The average value of this indice could be estimated as:

$$
C A I D I=\frac{T I E P I}{N I E P I}
$$

Being TIEPI and NIEPI explained in the following subsections.

\section{1) Equivalent interruption time data (TIEPI)}

The TIEPI is defined as:

$$
\text { TIEPI }=\frac{\sum_{i=1}^{K}(P I i \cdot H i)}{\sum(P I)}
$$

Where:

PIi is the installed power in the $\mathrm{MV} / \mathrm{LV}$ transformer plus the contracted power in
$\mathrm{MV}$,which is affected by the interruption $\mathrm{i}$ with a $\mathrm{H}$ duration.

Hi interruption time of the supply that affects the power PIi.

$\mathrm{K}$ number of interruptions during the periode.

PI total installed power in the $\mathrm{MV} / \mathrm{LV}$ transformer plus the contracted power in MV.

The interruptions considered are those larger than $3 \mathrm{~min}$. The data recollected concerning to the value of TIEPI for the 5 regions studied are given in table I.

Table I: TIEPI

\begin{tabular}{|l|c|c|c|c|r|}
\hline ZONE & Catalunya & Galicia & Andalucia & Madrid & Euskadi \\
\hline \hline Urban & 1.13 & 0.67 & 1.27 & 0.98 & 0.88 \\
\hline Semiurban & 1.91 & 3.32 & 2.15 & 2.01 & 1.76 \\
\hline Rural concentrated & 2.94 & 5.86 & 4.69 & 3.84 & 4.23 \\
\hline Rural dispersed & 3.69 & 3.66 & 5.75 & 6.52 & 13.12 \\
\hline \hline Total & 1.78 & 2.62 & 2.38 & 1.26 & 1.89 \\
\hline
\end{tabular}

Source: Statistical data of the Spanish Ministry of Industry.

Dowloadable from: https://oficinavirtual.mityc.es/eee/indiceCalidad/ccaa2.aspx

Data from every region has been divided in 4 different zones: urban (more than 20,000 supplies), semiurban (between 2,000 and 20,000 supplies), rural concentrated (between 200 and 2,000 supplies), rural dispersed (less than 200 supplies).

The TIEPI $80 \%$ is the reference used by the Spanish government in order to valorate the deviation in TIEPIs of the different communities. It is the boundary permited by the system and no zone in Spain is allowed go over this TIEPI $80 \%$ for more than two consecutives years.

2) Number of equivalent interruptions of the power supply (NIEPI)

The number of equivalent interruptions of the power supply (NIEPI) is defined as:

$N I E P I=\frac{\sum_{i=1}^{K}(P I i)}{\sum(P I)}$

Where:

PIi is the installed power in the MV/LV transformer plus the contracted power in $\mathrm{MV}$, which is affected by the interruption i with a $\mathrm{H}$ duration.

$\mathrm{K}$ number of interruptions during the periode.

PI total installed power in the $\mathrm{MV} / \mathrm{LV}$ transformer plus the contracted power in MV.

The interruptions considered are those larger than 3 min. The NIEPI data for the different regions analysed is given in table II. 
Table II: NIEPI

\begin{tabular}{|l|c|c|c|c|r|}
\hline ZONE & Catalunya & Galicia & Andalucia & Madrid & Euskadi \\
\hline \hline Urban & 1.63 & 1.06 & 1.79 & 1.62 & 0.78 \\
\hline Semiurban & 2.12 & 3.38 & 2.83 & 3.06 & 1.24 \\
\hline Rural concentrated & 2.66 & 5.24 & 5.18 & 5.80 & 1.93 \\
\hline Rural dispersed & 2.75 & 3.03 & 5.26 & 6.57 & 4.73 \\
\hline \hline Total & 2.00 & 2.72 & 2.82 & 2.01 & 1.20 \\
\hline
\end{tabular}

Source: Statistical data of the Spanish Ministry of Industry.

Dowloadable from: https://oficinavirtual.mityc.es/eee/indiceCalidod/ocaalaspx

3) Average duration of power interruptions

The average duration of power interruptions is usually evaluated with the indice CAIDI. An estimation of the CAIDI average value with no major event days can be considered as $53.57 \mathrm{~min}$, see reference [6].

In this example, the average duration of power interruptions will be assumed to be calculated with equation 3 . The results of the calculation are given in table III.

Table III: CAIDI

\begin{tabular}{|l|c|c|c|c|c|}
\hline \multirow{2}{*}{ ZONE } & \multicolumn{5}{|c|}{ INTERRUPTION DURATION [hours] } \\
\cline { 2 - 6 } & Catalunya & Galicia & Andalucia & Madrid & Euskadi \\
\hline \hline Urban & 1.44 & 1.58 & 1.41 & 1.65 & 0.89 \\
\hline Semiurban & 1.12 & 1.02 & 1.32 & 1.52 & 0.70 \\
\hline Rural concentrated & 0.90 & 0.89 & 1.10 & 1.51 & 0.46 \\
\hline Rural dispersed & 0.75 & 0.83 & 0.91 & 1.01 & 0.36 \\
\hline \hline Total & 1.12 & 1.04 & 1.14 & 1.60 & 0.63 \\
\hline
\end{tabular}

None of the CAIDI presented in table III exceeds the allowed limits. Therefore all of them will be subjected to the calculation. If one of them would be above limits, then it should be subjected to special consideration since there is a financial aid from the government for theses cases.

\section{B. Evaluation of the VoLL}

The VoLL represents the losses per hour of energy not supplied.

$$
\text { VoLL }=\frac{\text { GeneratedAddedValue }}{\text { EnergyConsumed }}
$$

Where the added value will be evaluated in the following subsections in current $€$. The energy consumed in [kWh] will be also evaluated in the following sections.

1) Added value in current prices

The added value of the production of the Spanish industry per year and in current prices will be obtained from the statistics of the Spanish government.

In the present case the data for the different sectors considerated: agriculture, energy, industry, construction and services has been taken from the Spanish government estatistics for the 5 regions considered and for the year 2006.

Those industry sectors and subsectors in order to apply the different TIEPIs has to be refered to a zone, meaning: urban, semi-urban, rural concentrated and rural dispersed.

The correspondence between those areas is not direct but it will be assumed as follows:

- Agriculture can be considered as mainly rural dispersed but fishing could be considered as rural concentrated

- In the energy sector, extraction of fuels could be considered rural dispersed but power industry, water and gas are mainly urban or semi-urban. Therefore it will be divided in between the two sectors $50 \%$ and $50 \%$.

- The industry sector is mainly urban and semiurban. Also $50 \%$ and $50 \%$.

- The construction sector has afected all the zones. It will be divided in the four different zones $25 \%$ for each.

- The services sector is also spread over the four different zones but maily urban and semi-urban. Also 50\% for each.

While accepting these assumptions, table IV can be constructed.

Table IV: Zonal added value in current prices (in thousands of euros) for 2006

(1n thousands of eurOS) for 2006
\begin{tabular}{|l|c|c|c|c|r|}
\hline ZONE & CATALUNYA & GALICIA & ANDALUCIA & MADRID & EUSKADI \\
\hline \hline Urban & $75,891,824$ & $19,512,666$ & $52,446,736$ & $73,038,237$ & $25,090,478$ \\
\hline Semi-urban & $75,891,824$ & $19,512,666$ & $52,446,736$ & $73,038,237$ & $25,090,478$ \\
\hline Rural concentrated & $4,430,798$ & $2,310,813$ & $4,760,196$ & $4,163,645$ & $1,437,089$ \\
\hline Rural dispersed & $7,573,614$ & $3,514,524$ & $11,250,508$ & $4,659,735$ & $2,373,152$ \\
\hline \hline Total Grass Added Value & $163,788,059$ & $44,850,667$ & $120,904,176$ & $154,899,854$ & $53,991,198$ \\
\hline
\end{tabular}

2) Annual energy consumption per regions

The data of the annual energy consumption per regions is available in the statistics, see reference [7], published by REE, see on table V.

Table V: Energy demand per regions for 2006 [GWh]

\begin{tabular}{|l|c|c|c|c|}
\hline CATALUNYA & GALICIA & ANDALUCIA & MADRID & EUSKADI \\
\hline \hline 46,379 & 19,082 & 38,926 & 30,468 & 20,703 \\
\hline
\end{tabular}

Source: Statistical data of REE.

Dowloadable from: https://wworee.es

3) Annual energy consumption per regions per zones

The distribution per zones will be done by supposing the same distribution of energy consumption as for power demand, see on table VI.

Table VI: Energy consumption in 2006 [GWh]

\begin{tabular}{|l|c|c|c|c|r|}
\hline ZONE & CATALUNYA & GALICIA & ANDALUCIA & MADRID & EUSKADI \\
\hline \hline Urban & $23,057.68$ & $7,302.41$ & $18,432.06$ & $23,907.29$ & $7,980.28$ \\
\hline Semi-urban & $14,704.97$ & $9,212.32$ & $12,644.25$ & $5,626.06$ & $9,265.07$ \\
\hline Rural concentrated & $4,031.24$ & $2,315.54$ & $2,332.06$ & 901.89 & $3,316.06$ \\
\hline Rural dispersed & $4,585.09$ & 251.71 & $5,517.61$ & 32.74 & 141.57 \\
\hline \hline Total & 46,379 & 19,082 & 38,926 & 30,468 & 20,703 \\
\hline
\end{tabular}

4) Value of Lost Load (VoLL)

The results of the application of equation (4) are presented in table VII. 
Table VII: VoLL in 2006 [€/ kWh]

\begin{tabular}{|l|c|c|c|c|r|}
\hline ZONE & CATALUNYA & GALICIA & ANDALUCIA & MADRID & EUSKADI \\
\hline \hline Urban & 3.29 & 2.67 & 2.85 & 3.06 & 3.14 \\
\hline Semi-urban & 5.16 & 2.12 & 4.15 & 12.98 & 2.71 \\
\hline Rural concentrated & 1.1 & 1 & 2.04 & 4.62 & 0.43 \\
\hline Rural dispersed & 1.65 & 13.96 & 2.04 & 142.33 & 16.76 \\
\hline \hline Total & 3.53 & 2.35 & 3.11 & 5.08 & 2.61 \\
\hline
\end{tabular}

\section{Evaluation of the ELP}

The equivalent lost power will be considered as peak power demand per zones and regions and it is given in VIII.

Table VIII: Peak power demand in 2006

\begin{tabular}{|l|c|c|c|c|c|}
\hline \multirow{2}{*}{ ZONE } & \multicolumn{5}{|c|}{ Peak power demand [MVA] } \\
\cline { 2 - 7 } & CATALUNYA & GALICIA & ANDALUCIA & MADRID & EUSKADI \\
\hline \hline Urban & $12,409.95$ & $2,285.73$ & $9,512.82$ & $11,536.26$ & $2,559.59$ \\
\hline Semiurban & $7,914.41$ & $2,883.55$ & $6,525.72$ & $2,714.81$ & $2,971.67$ \\
\hline Rural concentrated & $2,169.67$ & 724.79 & $1,203.58$ & 435.2 & $1,063.59$ \\
\hline Rural dispersed & $2,467.76$ & 78.79 & $2,847.65$ & 15.8 & 45.41 \\
\hline \hline Total & $24,961.79$ & $5,972.86$ & $20,089.77$ & $14,702.07$ & $6,640.26$ \\
\hline
\end{tabular}

Source: Statistical data of the Spanish Ministry of Industry.

Dowloadable from: https://oficinavirtul_mityc.es/ex/indiceCalidad/ocaalaspx

\section{Value of losses}

The calculation of Value of the losses is done by applying equation (1). The total results of the calculation for every zone and for every region are given in IX.

Table IX: Results of the calculation for the diferent zones and regions in 2006 [k€]

\begin{tabular}{|l|c|c|c|c|c|}
\hline \multirow{2}{*}{ ZONE } & \multicolumn{5}{|c|}{ Peak power demand [MVA] } \\
\cline { 2 - 6 } & CATALUNYA & GALICIA & ANDALUCIA & MADRID & EUSKADI \\
\hline \hline Urban & $12,409.95$ & $2,285.73$ & $9,512.82$ & $11,536.26$ & $2,559.59$ \\
\hline Semiurban & $7,914.41$ & $2,883.55$ & $6,525.72$ & $2,714.81$ & $2,971.67$ \\
\hline Rural concentrated & $2,169.67$ & 724.79 & $1,203.58$ & 435.2 & $1,063.59$ \\
\hline Rural dispersed & $2,467.76$ & 78.79 & $2,847.65$ & 15.8 & 45.41 \\
\hline \hline Total & $24,961.79$ & $5,972.86$ & $20,089.77$ & $14,702.07$ & $6,640.26$ \\
\hline
\end{tabular}

Source: Statistical data of the Spanish Ministry of Industry.

Dowloadable from: https://oficinavirtual.mityc.es/eee/indiceCalidad/ocaal. aspr

\section{E. Analysis of results}

The results obtained in table IX are the losses in thousands of Euros for every region analyzed on one side applying different TIEPIs and NIEPIs depending on the zone (rural or urban) and on the other side just applying the average numbers for TIEPI/NIEPI and production given by the Spanish government.

The results by using an average value of the CAIDI or different values depending on region are similar. The average deviation is $10 \%$, the maximal deviation is detected in Euskadi with a $17 \%$ deviation while the minimal is detected in Madrid with a $-2 \%$ deviation. The reason for that is atribuible to the differences in the CAIDI between rural and urban zones. Regions where the production of added value is mainly in urban zones, the differences are minimal, while zones where the production of added value is more distributed, the differences are higher.

\section{Conclusions}

This paper has developed a new methodology for calculating the losses of an industry based on the value of lost load. The data input for the methodology is both downladable and free of confidentiality issues. The sources of this information has been also provided and an example of application developed.

The example of application of the methodology is provided for 5 regions in Spain. This example takes into account the calculation based on average data directly retrieved from the statistics and a second calculation where the location of the industry has been taking into account.

As conclusions, the main strenghts of this new methodology have been identified. First, it is relativily easy to apply, as it has been shown in the example. Second, the information input is available and the source have been also localized. Third, it can be applied to different environments (insite and outsite the European region) and the source of information for every environment has also been provided. Four, it can give estimative results for every kind of industry and studied region.

Further work is necessary in order to evaluate the accuracy of the methodology.

\section{References}

[1] D. Coll-Mayor, J. Pardo, M. Pérez Donsión, "Analysis of methodologies for the economical evaluation of power quality", in Proc. ICREPQ09, online.

[2] M.F. McGranaghan and W.C. Roettger. The economics of custom power. In Transmission and Distribution Conference and Exposition, 2003 IEEE PES, volume 3, pages 944-948 vol.3, Sept. 2003.

[3] Mark McGranaghan and Bill Roettger. Economic evaluation of power quality. Power Engineering Review, IEEE, 22(2):8-12, Feb. 2002.

[4] K. G. Willis and G. D. Garrod. Electricity supply reliability : Estimating the value of lost load. Energy Policy, 25(1):97 - 103, 1997.

[5] Michiel de Nooij, Carl Koopmans, and Carlijn Bijvoet. The value of supply security: The costs of power interruptions: Economic input for damage reduction and investment in networks. Energy Economics, 29(2):277 - 295, 2007.

[6] Ieee guide for electric power distribution reliability indices, 2004.

[7] Informe anual: 2006. el sistema el'ectrico espa nol. Technical report, Red Electrica de España, Downloadable from: http://www.ree.es, 2006. 